\title{
Saldering van financiële activa en passiva onder IFRS
}

\section{Herbert Reimers}

SAMENVATTING Saldering van actief- en passiefposten is onder IAS 32 onder strikte voorwaarden verplicht. Er dient ten eerste een recht tot verrekening aanwezig te zijn en ten tweede moet de intentie bestaan dat recht daadwerkelijk uit te oefenen. Deze voorwaarden worden ook onder US GAAP gesteld, maar US GAAP staat bij het vervullen van de voorwaarden saldering toe. Verrekening is juridisch niet altijd toegestaan, zeker niet in geconsolideerde verhoudingen, en is door de juridische complexiteit soms moeilijk te beoordelen. Het intentievereiste moet worden beoordeeld aan de hand van de uitingen van het management en de omstandigheden. Dit maakt de beoordeling of saldering aan de orde is een juridische exercitie met aan het slot een lastig te objectiveren toetsing.

\section{Inleiding}

Saldering van financiële activa en verplichtingen heeft balansverkorting tot gevolg. Onder de Amerikaanse verslaggevingsvoorschriften (US GAAP) en onder de International Financial reporting Standards (IFRS) worden dezelfde voorwaarden voor saldering gesteld. Echter, waar IFRS bij vervulling van de voorwaarden saldering vervolgens verplicht, staat US GAAP saldering toe. Met een dergelijke verschillende behandeling komt de conceptuele vraag op of de strikte regels die IFRS stelt, wel juist zijn. Ik ga daar in deze bijdrage op in. Voordat aan deze conceptuele vraag over saldering toegekomen kan worden, ga ik eerst in op de twee voorwaarden die voor saldering worden gesteld. De eerste voorwaarde is de aanwezigheid van een juridisch recht om te verrekenen. De tweede voorwaarde

Mr. drs. H.K.O. Reimers AA CPA is als advocaat verbonden aan Van Doorne NV. betreft de aanwezigheid van een intentie om de te salderen posten daadwerkelijk te verrekenen of simultaan af te wikkelen.

Het is in veel gevallen niet eenvoudig om de aanwezigheid van een kwalificerend recht om te verrekenen vast te stellen. In de praktijk wordt de aanwezigheid van een dergelijk recht regelmatig ten onrechte aangenomen. Ten aanzien van de intentievoorwaarde blijkt in de praktijk vooral het aantonen van de intentie tot veel discussie te leiden.

Voordat ik tot mijn conclusie kom, zal ik een praktijkvoorbeeld behandelen waarin de voorwaarden die aan saldering worden gesteld naar voren komen.

\section{Principes en voorwaarden rondom saldering}

\subsection{Achtergrond}

Saldering moet worden onderscheiden van verrekening. Verrekening is de uitoefening van het recht om een vordering en een verplichting juridisch met elkaar te mogen verrekenen. Als gevolg van de verrekening vallen de vordering en verplichting (gedeeltelijk) tegen elkaar weg, waardoor juridisch een vordering of een verplichting ter hoogte van het nettobedrag resteert. Indien verrekening heeft plaatsgevonden resteert op de balans een vordering of schuld ter hoogte van dit nettobedrag. De verrekening heeft tot gevolg dat de verrekende bedragen van de balans afgevoerd worden.

Indien nog niet is verrekend, maar er vorderingen en schulden zijn die met elkaar verrekend mogen worden, komt de vraag op of gesaldeerde weergave van deze posities in de balans is toegestaan of zelfs verplicht is. Bij saldering worden voor verslaggevingsdoeleinden een actief- en een passiefpost samen voor het saldo van deze beiden in één actief- of passiefpost weergegeven. Dit heeft een balansverkorting tot gevolg. Van daadwerkelijke verrekening is op dat moment (nog) geen sprake. De vordering en de schuld 
blijven volledig bestaan. De door saldering ontstane afname van zowel het vreemd vermogen als de activa, heeft effect op diverse ratio's. Zo wordt bijvoorbeeld de solvabiliteitsratio door saldering positief beïnvloed. Het salderingsvraagstuk doet zich meestal voor in de situatie waarbij tussen twee entiteiten sprake is van wederzijds debiteurschap. Een entiteit heeft in die verhouding tot een andere entiteit zowel een vordering als een schuld. Daarnaast doet het vraagstuk zich ook voor bij het opstellen van de geconsolideerde jaarrekening. In dat geval komen bijvoorbeeld een vordering van de ene groepsmaatschappij en een schuld van een andere groepsmaatschappij aan dezelfde wederpartij, niet-groepsmaatschappij, in de geconsolideerde balans naar voren. Denk bijvoorbeeld aan de financiële relaties van de verschillende groepsmaatschappijen met de bank. Mag in de geconsolideerde jaarrekening saldering van de vordering van groepsmaatschappij A op de bank, met de schuld van groepsmaatschappij B aan de bank, plaatsvinden? Ik ga daar in paragraaf 3.5 nader op in.

\subsection{Voorwaarden voor saldering}

Bij de keuze voor gesaldeerde weergave staat de hoogte en de onzekerheid van de cash flow centraal. De onzekerheid ten aanzien van de cashflow vertaalt zich in het kredietrisico en liquiditeitsrisico. Kredietrisico is het risico dat de ene partij niet aan haar verplichtingen zal voldoen, waardoor de andere partij een financieel verlies te verwerken krijgt. Liquiditeitsrisico is het risico dat een partij niet de mogelijkheid heeft om de financiële middelen te verkrijgen die nodig zijn om aan de verplichtingen uit hoofde van de financiële instrumenten te voldoen. Indien een entiteit de vordering en de schuld gezamenlijk met één nettobetaling voldoet, is sprake van een enkele cash flow waarover krediet- of liquiditeitsrisico wordt gelopen. Hetzelfde geldt indien een entiteit de vordering en de schuld simultaan afwikkelt. Ook dan wordt slechts over het saldo van de beide cashflows krediet- of liquiditeitsrisico gelopen.

Weergave in de balans van slechts het saldo van de vordering en de schuld zal deze toekomstige cash flow waarover krediet- of liquiditeitsrisico wordt gelopen het beste weergeven. Bij de aanwezigheid van kredietrisico over de vordering (voor de positie als crediteur) of liquiditeitsrisico over de schuld (voor de positie als debiteur), wordt netto of simultane afwikkeling onzeker en daarmee ook de hoogte van de netto cash flow. Indien de krediet- en liquiditeitsrisico's zich uitstrekken tot het (gehele) bedrag van de vordering en de schuld, zal afzonderlijke opname als vordering en schuld de meest informatieve weergave van de financiële risico's van de onderneming zijn. Blijven deze risico's beperkt tot het saldo, dan zal gesaldeerde weergave aangewezen zijn.

De hiervoor geschetste principes worden vrijwel mondiaal geaccepteerd en voor de praktische toepassing weergegeven in twee voorwaarden:

1 Het kredietrisico en liquiditeitsrisico moet beperkt zijn tot het saldo van de te salderen actief- en passiefpost. Dit is in IAS 32.42 (vergelijk ook RJ 115.305 en voor US GAAP: FIN 39.5) zo omschreven dat voor saldering een entiteit een juridisch afdwingbaar recht moet hebben om een actief en een vreemd vermogenspost te verrekenen;

2 De cashflow (timing en bedrag) waarover krediet- of liquiditeitsrisico wordt gelopen moet beperkt zijn tot het saldo van de te salderen actief- en passiefpost. Dit is in IAS 32.42 (vergelijk ook RJ 115.305 en voor US GAAP: FIN 39.5) zo omschreven dat voor saldering een entiteit de intentie moet hebben om het actief en de vreemd vermogenspost te verrekenen of simultaan af te wikkelen.

Op beide voorwaarden zal in de volgende paragrafen nader worden ingegaan.

\section{Voorwaarde 1: Het juridisch afdwingbare recht}

\subsection{Verrekening algemeen}

Wij bekijken een voorbeeld waarin A en B over en weer geld te vorderen hebben. Indien A een bedrag van 100 te vorderen heeft van $B$, en $B$ een bedrag van 90 te vorderen heeft van $A$, is per saldo door B een bedrag van 10 verschuldigd aan A. Gesaldeerde weergave zou in de balans van A leiden tot opname van slechts een vordering van 10 . Niet gesaldeerde weergave zou in de balans van A leiden tot opname van een vordering van 100 en een schuld van 90 . In het faillissement van A zal, indien geen recht op verrekening bestaat, de curator 100 van B vorderen, terwijl B slechts een concurrente vordering heeft van 90, waarvan B mag hopen dat op deze vordering nog iets wordt uitgekeerd. In dit scenario beperkt het kredietrisico zich niet tot het saldo, waardoor op basis van voornoemd principe een gesaldeerde weergave niet correct is. Individuele opname van zowel de vordering als de schuld is verplicht.

Saldering vereist een juridisch afdwingbaar recht om een actief en een vreemd vermogenspost netto te verrekenen of simultaan af te wikkelen. Dit recht moet economisch tot gevolg hebben dat een actief en een vreemd vermogenspost door de verslaggevende 
entiteit te allen tijde netto verrekend of simultaan afgewikkeld kunnen worden. Bij verrekening wordt een schuld zodanig met een tegenvordering afgewikkeld dat slechts het saldo tussen beide bedragen overblijft als vordering of schuld. Dit recht is in Angelsaksische landen over het algemeen niet wettelijk geregeld en kan alleen contractueel overeengekomen worden. In continentaal Europa is verrekening veelal wel wettelijk geregeld. In sommige landen werkt de verrekening van rechtswege. Indien aan de wettelijke voorwaarden voor verrekening is voldaan, treden de rechtsgevolgen in en blijft slechts het saldo van de vordering en schuld over. In bijvoorbeeld Nederland is geen verplichting, maar een bevoegdheid tot verrekenen in de wet opgenomen. De rechtsgevolgen treden, indien aan de voorwaarden is voldaan niet van rechtswege in, maar pas als een beroep op de bevoegdheid wordt gedaan. In landen waar verrekening van rechtswege intreedt, kan het salderingsvraagstuk zich dus niet voordoen. Zodra immers het recht tot verrekenen aanwezig is, vindt verrekening plaats en is de vordering of schuld tot het saldo van beiden afgenomen. Bij salderingsvraagstukken zal het van toepassing zijnde recht daarom een grote rol spelen. Aan verrekening kan, zoals in Nederland, terugwerkende kracht verbonden zijn (art 6:129 BW). In dat geval zal verrekening na balansdatum maar voor de datum van opmaken van de jaarrekening terug kunnen werken tot op of voor de balansdatum. In dat geval mag van de verrekende vordering en schuld slechts het resterende saldo in de balans gepresenteerd worden. Het salderingsvraagstuk is dan niet meer aan de orde.

\subsection{Verrekening naar Nederlands recht}

Wat het Nederlands recht betreft, is een en ander in de artikelen 6:127 t/m 6:141 BW geregeld. Het betreft hier regelend recht. Dat betekent dat partijen bij overeenkomst de voorwaarden voor verrekening geheel zelf kunnen invullen en indien gewenst van de wettelijke regels mogen afwijken. Verrekening biedt de mogelijkheid dat ook in faillissement van de wederpartij een debiteur zijn schuld aan een wederpartij (gedeeltelijk) met zijn vordering op die wederpartij kan voldoen (art. 6:78/6:79 BW). Het kredietrisico bij faillissement is daarmee voor het verrekenbare bedrag uitgesloten.

De faillissementswet geeft in artikel $54 \mathrm{Fw}$. in samenhang met artikel 53 Fw. een aantal beperkingen aan verrekening die in dit verband van belang zijn. Ten eerste kunnen ná de faillietverklaring overgenomen schulden aan, of vorderingen op, de gefailleerde niet worden verrekend. Ten tweede mogen dergelijke schulden of vorderingen die vóór de faillietverklaring van een derde zijn overgenomen, niet worden verrekend, indien de overnemer bij de overneming niet te goeder trouw heeft gehandeld. Deze bepalingen betekenen een aanmerkelijke beperking voor de mogelijkheid tot verrekening, en daarmee voor saldering, op geconsolideerd niveau. In paragraaf $3.5 \mathrm{zal}$ ik daar nader op ingaan.

\subsection{Wie kan verrekenen?}

Om buiten faillissement tot verrekening over te kunnen gaan, hoeft alleen degene die wil verrekenen een opeisbare vordering te hebben. Het is dus aan de schuldeiser of hij van zijn verrekeningsrecht gebruik wil maken. De schuldeiser kan zijn niet opeisbare schuld aan de wederpartij middels verrekening met zijn opeisbare vordering op de wederpartij voldoen. Dit is anders indien de niet opeisbaarheid van de schuld aan de wederpartij voor de wederpartij een bepaald belang heeft. Een vordering is voorts niet afdwingbaar door de schuldeiser indien bijvoorbeeld aan een derde op de vordering een pandrecht is verleend. De vordering is niet opeisbaar indien de vordering voorwaardelijk is (vgl. art. 6:21 BW) of een ten behoeve van de schuldenaar opgenomen termijn nog niet is verstreken (vgl. art. 6:39 BW). Verrekening is bij het ontbreken van afdwingbaarheid of het ontbreken van opeisbaarheid dus niet mogelijk. In faillissement hoeft de vordering op de gefailleerde niet opeisbaar te zijn (HR 21 januari 1983, NJ 1983, 513).

Uitgewerkt in een voorbeeld heeft partij A een vordering op partij B. De vordering moet in juni van volgend jaar worden voldaan. Partij $B$ heeft een vordering op partij $\mathrm{A}$ die in april van volgend jaar moet worden voldaan. In dit geval kunnen niet beide partijen tot verrekening overgaan. Op het moment in juni dat partij A een opeisbare vordering heeft, heeft zij haar schuld al in april voldaan. Verrekening is dan niet meer mogelijk. Alleen partij B heeft een opeisbare vordering op het moment dat zijn schuld aan partij A nog niet is voldaan waardoor verrekening voor partij B mogelijk is.

\subsection{Te allen tijde kunnen verrekenen}

Vorderingen kunnen onderworpen zijn aan een voorwaarde. In het Nederlands recht wordt onderscheid gemaakt tussen opschortende en ontbindende voorwaarden. Een opschortende voorwaarde is niet afdwingbaar en verhindert daardoor de mogelijkheid tot verrekenen. IAS 32 stelt in par. 50 en de Application Guidance (AG38) dat voor saldering 
sprake moet zijn van een onvoorwaardelijk recht tot verrekening. Dat heeft bijvoorbeeld tot gevolg dat wanneer verrekening is onderworpen aan goedkeuring van de wederpartij, saldering niet is toegestaan. Beperking van de verrekening tot het geval van faillissement geeft aan de verrekening een voorwaardelijk karakter. Dit sluit saldering uit. Een zodanige beperking van verrekening waardoor bij faillissement verrekening niet mogelijk is, neemt mijns inziens ook de mogelijkheid tot saldering weg. Betoogd kan worden dat het recht tot verrekening bij faillissement voor het salderingsvraagstuk alleen van belang is, indien een faillissement op het verslaggevingsmoment aan de orde is. In overige gevallen zou van het continuiteitsbeginsel (going concern-beginsel) uitgegaan moeten worden. Daar staat tegenover, dat juridisch afdwingbaar pas betekenis heeft indien ook in faillissement verrekening kan worden afgedwongen. Het kredietrisico blijft zonder afdwingbaarheid in faillissement immers bestaan voor het gehele bedrag van de afzonderlijke posities en is niet beperkt tot het saldo van de afzonderlijke posities. Een recht dat niet kan worden uitgeoefend in faillissement past daar op basis van de eerder besproken principes niet in. In de Verenigde Staten is ten aanzien van saldering door de Emerging Issues Task Force (EITF) van de Financial Accounting Standards Board (FASB) een interpretatie afgegeven over juridisch afdwingbaar bij faillissement. Volgens deze interpretatie (interpretation No 39 EITF D-43) betekent juridisch afdwingbaar dat netto verrekening ook in faillissement van de debiteur afdwingbaar moet zijn. Mijns inziens moet deze laatste visie worden gevolgd. Dit betekent dat het recht van verrekening stand moet houden bij faillissement van de wederpartij van de verslaggevende entiteit.

\subsection{Verrekening op geconsolideerd niveau}

Groepsvennootschappen profiteren vaak gezamenlijk van een voor de gehele groep afgesloten financiering. De individuele vennootschappen hebben bijvoorbeeld ieder rekening-courantverhoudingen met dezelfde bank. Op het niveau van de enkelvoudige jaarrekening van de individuele groepsvennootschappen is saldering pas aan de orde indien een individuele groepsvennootschap zowel een debet- als een creditsaldo heeft bij dezelfde bank. Bij het opmaken van de geconsolideerde jaarrekening van de groep zullen diverse debet- en creditverhoudingen tussen de groepsmaatschappijen en de bank naar voren komen. Een vraag die op dat moment opkomt, is of deze verhoudingen met elkaar gesaldeerd weergegeven mogen worden in de geconsolideerde balans. De bijzonderheid doet zich hier voor, dat de geconsoli- deerde jaarrekening betrekking heeft op een economische eenheid, waarbinnen de juridische grenzen van de individuele groepsvennootschappen nog steeds aanwezig zijn. De mogelijkheid tot verrekenen over deze juridische grenzen heen, is niet vanzelfsprekend, maar is wel noodzakelijk om tot gesaldeerde weergave over te gaan. In geconsolideerde verhoudingen zullen de juridische rechten beoordeeld moeten worden op de economische mogelijkheid tot verrekenen of simultane afwikkeling die leidt tot beperking van het krediet- en liquiditeitsrisico.

\section{Faillissement van de bank bij groepsfinanciering}

Wij bezien een faillissement van de bank in de situatie waarbij verschillende groepsvennootschappen debeten creditposities bij de bank aanhouden. Als gevolg van het ontbreken van de juridische mogelijkheid tot verrekenen tussen de groepsmaatschappijen, zal een faillissement van de bank met zich meebrengen dat de curator van de bank de debetsaldi van de groepsvennootschappen zal innen, terwijl betaling van de creditsaldi van de groepsvennootschappen als concurrente vorderingen onzeker is. Het kredietrisico beperkt zich daardoor niet slechts tot het saldo van alle debet- en creditstanden. Omdat de bevoegdheid tot verrekenen ontbreekt indien de vordering en schuld in van elkaar gescheiden vermogens vallen (art. $53 \mathrm{Fw}$.), is saldering van de debet- en creditposities in de geconsolideerde jaarrekening in beginsel niet mogelijk. Wel kunnen (combinaties van) rechten bestaan die er toe leiden dat economisch te allen tijde verrekening kan plaatsvinden. Dit leidt soms tot juridisch complexe situaties. Afgaan op alleen de contractuele bepaling dat verrekening is toegestaan, kan tot een onjuiste beoordeling van de mogelijkheid tot verrekening leiden. Ter illustratie schets ik twee situaties: hoofdelijke verbondenheid en verpanding debetsaldi.

\section{a. Hoofdelijke verbondenheid}

Groepsvennootschappen hebben zich contractueel vaak hoofdelijk verbonden ten aanzien van de schulden aan de gezamenlijke financier. Dit biedt mogelijkheden tot verrekening. Hoofdelijke verbondenheid van debiteuren leidt ertoe, dat de schuldeiser van iedere debiteur nakoming kan eisen. Hij mag betaling door een andere dan de door hem uitgekozen schuldenaar niet afwijzen. Nakoming door één van deze debiteuren voor het geheel, bijvoorbeeld middels verrekening, leidt ook tot bevrijding van de andere debiteur. Verrekening is alleen mogelijk voor de debiteur die tevens een tegenvordering op de schuldeiser heeft. Bij een faillissement van de bank zal groepsmaat- 
schappij B, die zich hoofdelijk aansprakelijk heeft gesteld voor de schuld van groepsmaatschappij A aan de bank, deze laatste schuld met haar eigen vordering op de bank mogen voldoen. Zonder de aanwezige hoofdelijkheid is dat niet mogelijk en zal groepsmaatschappij A haar schuld moeten voldoen, terwijl groepsmaatschappij B haar vordering als concurrente vordering in kan dienen bij de curator van de bank. De uit hoofdelijk schuldenaarschap betalende debiteur krijgt in het algemeen een regresvordering op de overige debiteur(en) waardoor een intra-groepslening ontstaat.

Zoals in 3.4. besproken, is vereist dat verrekening ook mogelijk is in geval van faillissement van de wederpartij van het concern, bijvoorbeeld de bank. Daarvoor is van belang dat de beperkingen die artikel 53 Fw. opwerpt, worden weerstaan. De Hoge Raad heeft daarover het volgende overwogen:

"De wetgever heeft, door in art 53 (FW) de formule voortvloeien uit handelingen vóór de faillietverklaring verricht' te gebruiken, de mogelijkheid van een beroep op compensatie geopend voor het geval de schuldeiser van de boedel aan deze een schuld heeft die, hoewel zij niet vóór de faillietverklaring is ontstaan, uit de afwikkeling van een vóór de faillietverklaring tot stand gekomen rechtsbetrekking voortvloeit. HR 26 maart 1976,NJ 1977, 612 (m.nt. B.W.), (Keulen q.q./Cebeco)."

Uit deze uitspraak mag geconcludeerd worden dat voor rechtsbetrekkingen zoals hoofdelijkheid, indien zij vóór de faillietverklaring tot stand zijn gekomen, verrekening mogelijk is. In HR 18 december 1992, RvdW 1993, 18; NJ 1993, 734 (m.nt. PvS) (Harko/ Groen-Kelderman q.q.) wordt deze conclusie bevestigd: bevrijdende betaling onder hoofdelijke verbondenheid werkt ook in geval van faillissement van de wederpartij van de groep. De hoofdelijke verbondenheid zorgt ervoor dat in geval van faillissement van de wederpartij, bijvoorbeeld de bank, de hiervoor besproken toepassing van art. $53 \mathrm{Fw}$. niet aan de orde komt en verrekening toch mogelijk is. In de praktijk wordt een belangrijke beperking van deze verrekeningsmogelijkheid opgeroepen door een aan de bank verleend pandrecht op de creditsaldi ter voldoening van de debetsaldi van de groep. De bank verkrijgt door dit pandrecht extra zekerheid dat de schulden van de groepsvennootschappen worden voldaan. De groepsvennootschap die een verpande vordering heeft op de bank kan deze niet voor verrekening aanwenden. Als gevolg van het verleende pandrecht is de mogelijkheid tot verrekening en daarmee tot saldering afwezig.

\section{b. Verpanding debetsaldi}

Een andere mogelijkheid is het verpanden van de debetsaldi door de bank aan de moedermaatschappij van de groep. Dit geeft de moedermaatschappij de benodigde zekerheid dat de creditsaldi van de groepsmaatschappijen ten minste tot het beloop van de debetsaldi van de groepsmaatschappijen zullen worden voldaan. De pandhouder (i.c. de moedermaatschappij) is bevoegd nakoming te eisen van de vordering waarop het pandrecht rust en betalingen in ontvangst te nemen (art. 3:246 lid1 BW). Effectief is het kredietrisico voor de moedermaatschappij beperkt tot het verschil tussen de credit- en de debetstand. Indien tevens de intentie tot verrekening bestaat, moeten de debet- en creditstanden gesaldeerd in de balans weergegeven worden. De bank zal in de praktijk veelal aarzelend tegenover het verstrekken van een pandrecht staan. Indien de bank ook zelf een pandrecht in de betreffende relatie houdt, op de creditsaldi, zullen de pandrechten botsen.

\subsection{De belangrijkste stappen naar het recht van verrekening}

Zoals hiervoor werd besproken, is er een flink aantal horden te nemen voordat een wettelijk of contractueel recht tot verrekening onder het van toepassing zijnde recht aanwezig is.

Ik vat de belangrijkste eisen hierna kort samen:

- alleen degene met de kortste resterende looptijd van zijn vordering heeft de mogelijkheid tot verrekening;

- verrekening moet onder alle gevallen mogelijk zijn, ook in geval van faillissement;

- voor posities met derden in de geconsolideerde jaarrekening kunnen de juridische grenzen tussen de groepsvennootschappen verrekening verhinderen;

- verstrekte zekerheid zoals bijvoorbeeld een pandrecht kan aan verrekening in de weg staan;

- de verrekening kan terugwerken tot op of voor de balansdatum.

\section{Voorwaarde 2: De Intentie}

\subsection{Algemeen}

Aanwezigheid van het hiervoor behandelde juridisch afdwingbaar recht om te verrekenen, is voor saldering niet voldoende. Ook moet de intentie bestaan om de posities netto te verrekenen of simultaan af te wikkelen. Deze voorwaarde is opgenomen omdat het kredietrisico voor het verrekenbare bedrag pas volledig verdwijnt indien daadwerkelijke netto verrekening of simultane afwikkeling plaatsvindt.

In veel gevallen is men zich niet bewust van het bestaan van een verrekeningsrecht, bijvoorbeeld 
wegens onbekendheid met de verschillende posities of onbekendheid met het verrekeningsrecht. Zeker in meerpartijenverhoudingen kan het recht moeilijk te duiden zijn. In situaties waarin wel bekendheid met het recht in een concrete situatie bestaat, kan het ongewenst zijn van het verrekeningsrecht gebruik te maken. Verrekening of simultane afwikkeling wordt in al deze situaties niet beoogd en vindt daardoor uiteindelijk niet plaats. Zodra in dat geval één van de posities wordt afgewikkeld, wijzigt het risico. Daardoor wordt niet voldaan aan de voorwaarde dat het kredietrisico gedurende de gehele looptijd tot het saldo beperkt blijft. Vanuit deze achtergrond is saldering vervolgens niet toegestaan. In IAS 32 wordt ter illustratie een (extreem) voorbeeld gegeven:

Een recht van verrekening bestaat en op dezelfde dag moeten de betalingen over en weer worden voldaan. Indien geen gesaldeerde afwikkeling plaatsvindt maar op de dag van betaling de beide bedragen afzonderlijk in hun geheel worden overgemaakt, bestaat gedurende een kort moment over het als laatste openstaande bedrag het volledige krediet- en liquiditeitsrisico. Op basis van voornoemd principe mag gesaldeerde weergave in de balans niet plaatsvinden. Het risico is immers niet te allen tijde beperkt tot het saldo.

De intentievoorwaarde vereist derhalve het beogen van een netto verrekening of simultane afwikkeling door de verslaggevende entiteit. Deze intentie hoeft in beginsel niet te worden bewezen, maar kan blijken uit bijvoorbeeld verklaringen van het management. Daarbij moeten de relevante omstandigheden en bedrijfsprocedures die de mogelijkheid tot verrekening beperken, wel meegewogen worden. Ook handelingen in het verleden zullen een indicatie zijn voor het daadwerkelijk gesaldeerd willen afwikkelen in de toekomst. Het volhouden van de intentie zal moeilijker worden indien in de praktijk blijkt dat posities individueel worden afgewikkeld en de voorgenomen netto verrekening of simultane afwikkeling uitblijft.

\subsection{Rekening-courantposities/wisselende posities}

Een bijzondere situatie doet zich voor indien sprake is van rekening-courantposities met een financier. Gedacht kan worden aan de bank die een lening heeft verstrekt en waar tevens de betaalrekening wordt aangehouden of aan een groep waarvan de verschillende groepsmaatschappijen debet- of creditposities bij de bank innemen. Vaak is er sprake van een langetermijnverhouding en veel tussentijdse transacties met derden. In de documentatie rond de verhouding met de bank is meestal opgenomen dat verrekening is toegestaan en dat bij faillissement en beëindiging van de relatie, de posities middels netto verrekening worden afgewikkeld. De lange termijn waarop de netto verrekening uiteindelijk plaatsvindt, maakt het lastig om bewijs van de netto verrekening in de praktijk te zien. De vele transacties met derden leiden er toe dat het in de jaarrekening weergegeven saldo fors kan afwijken van het saldo dat uiteindelijk middels verrekening wordt afgewikkeld. De documentatie geeft echter een sterke aanwijzing dat beëindiging van de posities alleen middels netto verrekening zal plaatsvinden. Als het management vervolgens de intentie tot verrekening uitspreekt terwijl van het tegendeel niets blijkt, is saldering van deze posities mijns inziens verplicht. Het risico op de posities is in deze verhouding immers te allen tijde tot het saldo beperkt door de anwezigheid van het recht om te verrekenen en de intentie om de posities uiteindelijk netto te verrekenen. De uiteindelijke cash flow beperkt zich door de tussentijdse mutaties weliswaar niet tot het saldo dat in de jaarrekening is opgenomen, maar wel tot het saldo van de debet- en creditpositie op het moment van verrekenen. De gesaldeerde weergave laat het risico zien dat over de gesaldeerde posities wordt gelopen.

In de praktijk wordt voor het volhouden van de intentie wel vereist dat een daadwerkelijke netto verrekening of simultane afwikkeling per verslagperiode plaatsvindt. Dit is een beduidend zwaardere eis dan door IAS 32 gesteld wordt. Als "safe harbour"-regeling voor twijfelachtige gevallen kan dit vereiste prima dienst doen. Vraag is nog wel of een partiële verrekening onder deze regeling de intentie ook voldoende aantoont. Direct terugboeken van de posities na een toegepaste verrekening doet het voldoen aan de intentie weer teniet.

\section{5 \\ Saldering, verplicht of toegestaan}

Indien aan één van de twee voorwaarden niet is voldaan, is saldering zowel onder IAS 32 als onder US GAAP niet toegestaan. Indien aan beide voorwaarden wel is voldaan, stelt IAS 32 saldering verplicht, waar US GAAP saldering toestaat. Welke benadering heeft de voorkeur?

De jaarrekening moet een getrouw beeld geven omtrent de financiële positie en prestaties en de kasstromen van een onderneming (IAS 1.10), een eis die ook in artikel 2:362 lid 1 BW teruggevonden wordt. Het getrouwe beeld vraagt om een juiste weergave van de hoogte en onzekerheid van de cashflow 
uit vorderingen en schulden. Indien aan beide voorwaarden voor saldering is voldaan, is feitelijk sprake van één cash flow, die naar mijn mening voor het getrouwe beeld het beste in één post weergegeven kan worden (In gelijke zin Beckman, 1999, p. 39).

Het in dergelijke gevallen toestaan en niet verplichten, doet niet alleen afbreuk aan het getrouwe beeld, maar heeft ook tot gevolg dat de vergelijkbaarheid van jaarrekeningen afneemt. In Fin 39.24 wordt de keuze voor het toestaan onder US GAAP verdedigd met een kosten/batenargument. Gesaldeerde weergave zou in een aantal gevallen te kostbaar kunnen zijn en zwaarder wegen dan de eis van vergelijkbaarheid. Indien aan beide voorwaarden is voldaan, zullen de verschillende saldeerbare posities echter al duidelijk in beeld gebracht zijn. Mijns inziens zullen de extra kosten die vervolgens nodig zijn voor een gesaldeerde weergave niet op kunnen wegen tegen het vereiste van het getrouwe beeld. Alleen de door IAS 32 voorgeschreven verplichting is daarom mijns inziens juist.

\section{Saldering in de praktijk: Cash management}

De verschillende maatschappijen in een groep hebben vaak individuele rekeningen bij een gezamenlijke bank. Om de verschuldigde en te ontvangen rente op deze rekeningen voor de groep als geheel te optimaliseren, maakt de groep vaak gebruik van het door de bank aangeboden cash management. Twee vormen van cash management kunnen worden onderscheiden, namelijk zero balancing en rentecompensatie. Balansverkorting, of het voorkomen van balansverlenging door saldering zal hierna voor beide vormen worden geanalyseerd.

\section{Vorm 1: Zero balancing}

Bij zero balancing worden periodiek, bijvoorbeeld eindedags of eindeweeks, debet- en creditposities van de groepsmaatschappijen naar nul geboekt, met een tegenboeking van een centrale rekening van de groep bij de bank, de "masteraccount". Dit leidt er voor de groep als geheel toe dat effectief aan het einde van de dag of week in de relatie met de bank slechts de nettopositie openstaat en daardoor slechts over de nettopositie krediet- en liquiditeitsrisico wordt gelopen. Zonder zero balancing zou in beginsel over alle creditsaldi volledig kredietrisico worden gelopen, zonder dat de debetsaldi dit risico zouden verminderen. Zero balancing leidt daarom tot een verlaging van het krediet- en liquiditeitsrisico. Indien de groepsvennootschappen over minimumsaldi moeten blijven beschikken, worden de posities van de groepsmaatschappijen door overboekingen van en naar de "master account" naar deze minimumsaldi gebracht ("constant balancing"). Door zero balancing ontstaan intragroepsvorderingen en -schulden. De overboeking van een creditsaldo naar de "masteraccount" van een andere groepsmaatschappij leidt immers tot een vordering op die groepsmaatschappij. Dit verhoogt het totaal van de rentestromen, die onderworpen kunnen zijn aan bronbelasting. Beide aspecten maken zero balancing soms onaantrekkelijk. Door de verlaging van het krediet- en liquiditeitsrisico en daarmee de effectuering van de positie tot het saldo, komt het salderingsvraagstuk bij zero balancing niet meer in beeld. Volstaan moet worden met opname van de tot het saldo teruggebrachte positie.

In varianten waarbij de groep zelf, zonder toestemming van de wederpartij, de mogelijkheid tot verrekening heeft, en dat niet automatisch geschiedt, wordt in ieder geval voldaan aan de voorwaarde van de juridische afdwingbaarheid ten aanzien van de verrekening. Om vervolgens onder IAS 32.42 en RJ 115.305 te kunnen salderen, zal echter ook aan de intentievoorwaarde voldaan moeten zijn. Zoals hiervoor aangegeven is in beginsel de geuite intentie van het management voldoende. Gezien de vaak lange looptijd is ondersteunend bewijs gewenst. De beoogde verrekening kan blijken uit een in de leningdocumentatie overeengekomen netto verrekening bij beëindiging, al dan niet door faillissement, van de relatie tussen de wederpartij en de groep. Een periodieke zero balancing zal kunnen volstaan. Deze zero balancing hoeft niet op de verslaggevingsdatum plaats te vinden. Indien deze wel op de verslaggevingsdatum plaatsvindt, heeft verrekening feitelijk plaatsgevonden en is nog slechts sprake van een debet- óf een creditpositie ter hoogte van het saldo. Voorwaarde is wel dat geen afspraak is gemaakt een en ander na balansdatum onmiddellijk terug te draaien. IAS 32.42 en RJ 115.305 komen dan niet meer in beeld.

\section{Vorm 2: Rentecompensatie}

Bij rentecompensatie ("notional cash pooling") worden debet- en creditsaldi van groepsmaatschappijen voor de berekening van de verschuldigde/te ontvangen rente met elkaar gesaldeerd. Deze saldering vindt alleen plaats ten behoeve van de rentecalculatie en niet ter bepaling van de nettopositie. Er is derhalve geen verlaging van het krediet- en liquiditeitsrisico.

Onder IAS 32.42 en RJ 115.305 bestaat bij zuivere rentecompensatie geen mogelijkheid tot gesaldeerde weergave van de binnen de pool bestaande debet- en 
creditposities. Het juridische recht tot verrekening ontbreekt immers. Om toch tot de veelal gewenste saldering over te kunnen gaan, zal de rentecompensatieovereenkomst aangepast moeten worden. De aanpassing zal tot gevolg moeten hebben dat de groepsvennootschappen de juridische mogelijkheid krijgen om te allen tijde, ook bij faillissement van de bank, debetsaldi met creditsaldi van andere groepsmaatschappijen te kunnen voldoen. In de praktijk ontbreekt bij de notional pool ook vaak de intentie om te verrekenen. Daar zal het management zich over moeten buigen.

Een minder vergaande oplossing is om op het verslaggevingsmoment, bijvoorbeeld einde kwartaal en einde jaar, de saldi zo laag mogelijk te houden. Dit kan door op de verslaggevingsdata een "periodieke zero- of constant balancing" toe te passen. Voorwaarde is wel dat geen afspraak is gemaakt een en ander na balansdatum onmiddellijk terug te draaien. Deze oplossing haalt de gehele salderingsdiscussie van tafel, maar leidt wel tot intragroepsleningen.

\section{Conclusie}

Saldering is onder IAS verplicht en onder US GAAP toegestaan indien het risico over een financieel actief en een financiële verplichting zich te allen tijde uitstrekt tot slechts het saldo van het financieel actief en de financiële verplichting. De keuze die door het "toestaan" onder US GAAP wordt geboden, doet afbreuk aan het getrouwe beeld en de vergelijkbaarheid. De verplichting onder IAS heeft mijns inziens duidelijk de voorkeur. Om aan saldering toe te komen, moet aan twee voorwaarden zijn voldaan. Deze voorwaarden houden in dat naast het bestaan van een juridisch recht om te verrekenen ook de intentie aanwezig moet zijn om netto te verrekenen of simultaan af te wikkelen. De intentievoorwaarde brengt ten opzichte van de andere voorwaarde zowel een aanscherping als een verlichting. Het management heeft, indien aan het vereiste van het juridische recht tot verrekening is voldaan, saldering in de hand door netto verrekening of simultane afwikkeling te beogen of niet te beogen. De aanscherping komt vooral naar voren in situaties waarin werd gesaldeerd omdat aan de voorwaarde van het juridische recht tot verrekening werd voldaan, maar netto verrekening of simultane afwikkeling nooit werd beoogd.

Een belangrijk aspect blijft de voorwaarde van de juridische verplichting waar in de praktijk vaak vrij gemakkelijk aan voorbij gegaan wordt. Een contractuele bepaling waarin staat "verrekening is te allen tijde mogelijk" is vaak niet voldoende. Zeker bij de wens van saldering op geconsolideerd niveau is invulling van deze voorwaarde complex en vraagt om de nodige zorgvuldigheid bij het opstellen van de leningdocumentatie. Bijvoorbeeld bij zuivere "notional cash pools" strandt de wens tot saldering vaak al bij het juridisch recht tot verrekening. Aanpassing van de leningdocumentatie kan er voor zorgen dat aan deze voorwaarde wordt voldaan. Het intentievereiste blijkt in een aantal praktijksituaties lastig aan te tonen. In de praktijk wordt daartoe een "safe harbour"-regel gehanteerd. Er moet echter voor gewaakt worden dat de hoofdregel niet wordt vervangen door de "safe harbour"-regel die een beduidend zwaardere eis inhoudt dan in IAS 32.42 gesteld wordt.

\footnotetext{
Literatuur

Beckman, H., (1999), Is saldering van op de balansdatum bestaande vorderingen en schulden tussen dezelfde partijen onder omstandigheden aanvaardbaar, in: A.J. Bindenga, M.A. van Hoepen en J. Maat (red.), Bericht gegeven, opstellenbundel aangeboden aan Prof. drs. F. Krens, Kluwer, Deventer, pp. 29-42.

Financial Accounting Standards Board, Interpretation 39 (FIN 39): Offsetting of Amounts Related to Certain Contracts-an interpretation of APB Opinion No. 10 and FASB Statement No. 105.

Financial Accounting Standards Board, Emerging Issues Task Force (EITF), Interpretation No 39 EITF D-43.

HR 26 maart 1976,NJ 1977, 612 (m.nt. B.W.), (Keulen q.q./Cebeco).

HR 21 januari 1983, NJ 1983, 513.

HR 18 december 1992, RvdW 1993, 18; NJ 1993, 734 (m.nt. PvS) (Harko/ Groen-Kelderman q.q.).

International Accounting Standards Board, International Accounting Standard 32 (IAS 32), Financial Instruments: Disclosure and Presentation. Raad voor de Jaarverslaggeving, Richtlijnen voor de Jaarverslaggeving 2005, RJ 115.3 Verrekenen en salderen.
} 